\title{
Concanavalin A-induced Liver Injury Triggers Hepatocyte Proliferation
}

\author{
Christian Trautwein, ${ }^{*}$ Tim Rakemann, ${ }^{*}$ Nisar Peter Malek, ${ }^{*}$ Jörg Plümpe, ${ }^{*}$ Gisa Tiegs, ${ }^{\ddagger}$ and Michael Peter Manns \\ *Department of Gastroenterology and Hepatology, Medical Hochschule Hannover, 30625 Hannover, Germany, and ${ }^{\ddagger}$ Institute of \\ Pharmacology and Toxicology, University of Erlangen, 91054 Erlangen, Germany
}

\begin{abstract}
Concanavalin A (Con A) injection into mice leads to immune-mediated liver injury. We studied whether after Con A-induced liver injury, TNF- and IL-6-dependent signaling pathways known to be related to hepatocyte proliferation are activated. $2 \mathrm{~h}$ after Con $\mathrm{A}$ injection, maximum TNF- $\alpha$, and after 4-8 h, maximum IL-6 serum levels were found. The rise in aminotransferases and DNA fragmentation started after $4 \mathrm{~h}$; maximum levels were evident after $8 \mathrm{~h}$. 5-Bromo2 '-deoxyuridine staining and nuclear cyclin A expression as markers of the S-phase were first detected in hepatocyte nuclei after $24 \mathrm{~h}$, peaking after $48 \mathrm{~h}$. An increase in TNFdependent nuclear expression of CCAAT/enhancer-binding protein- $\beta$ (C/EBP- $\beta) /$ liver-enriched activating protein (LAP) was detected after $1 \mathrm{~h}$, whereas an increase in RNA expression was evident only after $4 \mathrm{~h}$. C/EBP- $\beta$ /LAP expression returned to normal values before progression into the S-phase. DNA binding of signal transducer and activator of transcription (STAT) 3/acute phase response factor (APRF) increased for up to $8 \mathrm{~h}$. As found by supershift experiments, in addition to STAT3/APRF, STAT1 also binds to the same sequence. During the course of time gel shift experiments, DNA binding of the apoptosis-related STAT1 started earlier than DNA binding of STAT3/APRF, which regulates hepatocyte proliferation. However, the subsequent decrease in DNA binding of both factors was comparable. This study demonstrates that after Con A injection, TNF- and IL-6dependent signals trigger nuclear events regulating hepatocyte apoptosis and proliferation during liver injury. (J. Clin. Invest. 1998. 101:1960-1969.) Key words: apoptosis • cell cycle $\bullet$ interleukin $6 \cdot$ tumor necrosis factor- $\alpha \cdot$ hepatocytes
\end{abstract}

\section{Introduction}

The differentiated hepatocyte is important for the maintenance of several functions crucial for the balance of life. Upon injury, liver cells have the capacity to proliferate and restore the original liver mass. Different pathophysiological conditions are associated with liver cell injury. Most of our current

Address correspondence to Christian Trautwein, M.D., Department of Gastroenterology and Hepatology, Medizinische Hochschule Hannover, Carl-Neuberg-Strasse 1, 30625 Hannover, Germany. Phone: 49-511-532-3489; FAX: 49-511-532-4896; E-mail: trautwein.christian@ mh-hannover.de

Received for publication 28 April 1997 and accepted in revised form 24 February 1998.

J. Clin. Invest.

(C) The American Society for Clinical Investigation, Inc. 0021-9738/98/05/1960/10 \$2.00

Volume 101, Number 9, May 1998, 1960-1969

http://www.jci.org knowledge of the mechanisms inducing hepatocyte proliferation after liver injury is based on experiments performed after two-thirds hepatectomy (1). Therefore, other models leading to liver cell injury and hepatocyte proliferation are needed. These models should provide insight into the molecular mechanisms involved in mediating the switch of hepatocytes from the resting G0-phase into the cell cycle, which will also have implications for the pathogenesis of liver disease in humans.

Concanavalin $\mathrm{A}(\mathrm{Con} \mathrm{A})^{1}$ injection into mice leads to immune-mediated liver injury (2). Con A has high affinity towards the hepatic sinus which results in the activation of $\mathrm{T}$ cells in the liver tissue $(3,4)$. Particularly, a subset of T lymphocytes-the $\mathrm{CD}^{+}$cells-are activated, which mediate liver injury. The activation of cells in the liver results in secretion of several cytokines involved in cell-cell communication and in mediating inflammation.

In human autoimmune liver disease, $\mathrm{CD}^{+} \mathrm{T}$ cells represent the predominant population of $\mathrm{T}$ cells infiltrating into the liver (5). Additionally, in chronic active hepatitis $\mathrm{B}$ or $\mathrm{C}$, the activity of the disease has been shown to be related to a $\mathrm{T}$ helper 1-like cytokine response of intrahepatic $\mathrm{CD}^{+} \mathrm{T}$ cells (6-8). T helper 1 cells release proinflammatory cytokines such as IFN- $\gamma$ or TNF. After Con A-induced hepatic injury, high levels of the cytokines IL-2, TNF- $\alpha$, IFN- $\gamma$, IL- 6 , GM-CSF, and IL-1 were found $(2,4,9)$. The role of some of these cytokines during Con $\mathrm{A}$-induced acute liver failure has been characterized in more detail. TNF- $\alpha$ and IFN- $\gamma$ have direct implications for the induction of apoptosis, as anti-TNF and anti-IFN pretreatment protect from liver injury $(3,9)$. In contrast, IL-6 seems to have a protective role, as IL-6 administration before Con A injection prevents mice from liver injury (4).

Con A injection has a dose-dependent effect on liver injury (2). Although high doses lead to severe liver failure and death of the treated animals, moderate doses result in a dramatic rise in aminotransferases, and at later time points, liver function is completely reconstituted $(2,4)$. The mechanisms involved in reconstitution of original liver function have not been analyzed to date. However, repair mechanisms including regenerative processes may be essential to restore liver function.

Recent experiments provided information that in addition to their role in liver cell damage, cytokines have important functions in the process of organ reconstitution $(10,11)$. Particularly during the early transition phase, which triggers the switch of hepatocytes from G0 into the cell cycle, cytokines induce mechanisms crucial for this process. The role of cytokines-such as IL- 6 and TNF- $\alpha$ - which are also involved in activating the acute phase response of the liver, have been studied in more detail during liver regeneration. IL-6 induces

1. Abbreviations used in this paper: APRF, acute phase response factor; BrdU, 5-bromo-2'-deoxyuridine; C/EBP, CCAAT/enhancer-binding protein; Con A, concanavalin A; LAP, liver-enriched activating protein; STAT, signal transducer and activator of transcription. 
nuclear translocation of a transcription factor called either acute phase response factor (APRF) or signal transducer and activator of transcription (STAT) $3(12,13)$. Nuclear translocation of STAT3/APRF is an early event during liver regeneration $(14,15)$. Activation of STAT3/APRF is impaired in IL-6 knockout mice and results in a lack of hepatocyte proliferation and thus liver regeneration (10). Several intracellular signaling cascades are activated by TNF. During liver regeneration after two-thirds hepatectomy, two families of transcription factors, activator protein 1 and CCAAT/enhancer-binding protein $(\mathrm{C} /$ EBP), are controlled by TNF and directly involved in hepatocyte proliferation during the early transition phase $(10,16,17)$.

The situation after Con A-induced liver injury is complex. In this model, the same cytokines may be important to induce either apoptosis or cell proliferation of hepatocytes. Therefore, studying the intracellular events which result in liver regeneration may also help to understand mechanisms preventing liver cell death. As similar biological functions exerted by $\mathrm{CD}^{+} \mathrm{T}$ cells are important during viral and autoimmune hepatitis, the Con A model might also provide a model system to investigate the pathogenesis of human liver diseases. Here we studied cell cycle progression after Con A-induced liver injury. We show that hepatocytes enter the S-phase 24-48 h after Con A injection. Regulation of the C/EBP proteins and STAT3/APRF was found before the G1/S-phase transition, which indicates that both intracellular signaling cascades may also be critical to trigger cell cycle progression in this model.

\section{Methods}

Animals, Con A injection, and preparation of liver nuclear extracts. Pathogen-free male BALB/c mice were obtained from the Animal Research Institute of the Medizinische Hochschule Hannover. All the experiments were begun between 8:00 and 10:00 a.m. and were performed in agreement with the German legal requirements. Animals were anesthetized by intraperitoneal injection of a combination of rompun and ketamine as indicated previously (18). For each time point, at least four animals were treated in parallel.

Con A $(20 \mathrm{mg} / \mathrm{kg})$ was injected intravenously. Anti-TNF IgG was administered 15 min before Con A injection when indicated $(2,3)$. In control-treated animals, only the carrier solution (PBS) was injected. At the indicated time points, a small subxyphoid incision was made, blood was taken, and the liver was removed. The livers from animals treated in parallel were pooled. Part of the liver was frozen for Northern blot analysis, immunofluorescence studies, and DNA fragmentation assays. The remaining liver was used to prepare liver nuclear extracts.

For preparation of nuclear extracts, the pooled livers were rinsed in ice-cold PBS, and liver nuclear proteins were prepared as described previously (18). All steps were performed at $4^{\circ} \mathrm{C}$. Nuclear proteins were aliquoted and frozen immediately in liquid nitrogen.

Cytokine and aminotransferase determinations. For cytokine determinations, blood was withdrawn into heparinized syringes by puncture of the right atrium. After a short spin at $200 \mathrm{~g}$, plasma was recovered and stored at $-80^{\circ} \mathrm{C}$ until use for determination of cytokine levels and aminotransferases.

TNF and IL-6 levels were determined by a commercially available ELISA (PharMingen Europe, Hamburg, Germany) according to the manufacturer's instructions. Alanine aminotransferase activities in plasma were determined by an automated enzyme assay as described previously (2).

SDS-PAGE and Western blot analysis. Liver nuclear proteins were separated on a $10 \%$ SDS-polyacrylamide gel (19) and blotted onto a nitrocellulose membrane (Schleicher \& Schuell, Inc., Keene, NH) in $1 \%$ SDS, $20 \%$ methanol, $400 \mathrm{mM}$ glycine, $50 \mathrm{mM}$ Tris- $\mathrm{HCl}$, $\mathrm{pH} 8.3$, at $4^{\circ} \mathrm{C}$ for $2 \mathrm{~h}$ at $200 \mathrm{~mA}$. Cyclin A, C/EBP- $\alpha$, and STAT3 were analyzed using antibodies directed against each of the proteins as supplied by Santa Cruz Biotechnology, Inc. (Santa Cruz, CA). The polyclonal antibody against $\mathrm{C} / \mathrm{EBP}-\beta /$ liver-enriched activating protein (LAP) has been described previously (19). The antigen-antibody complexes were visualized using the ECL detection system as recommended by the manufacturer (Amersham Buchler GmbH, Braunschweig, Germany).

Gel retardation assays. For gel retardation assays, liver nuclear extracts were used as indicated. Binding reaction was performed for $20 \mathrm{~min}$ on ice (20). For binding assays, an oligonucleotide spanning the STAT3 binding site derived from the $\alpha 2$-macroglobulin promoter (5'-GAT CCT TCT GGG AAT TCC TAG TAG-3') or an oligonucleotide spanning the $\mathrm{D}$ site of the albumin promoter $\left(5^{\prime}\right.$-TGG TAT GAT TTT GTA ATG GGG-3') was used as a ${ }^{32} \mathrm{P}$-labeled probe as described previously (20). Free DNA and DNA-protein complexes were resolved on a $6 \%$ polyacrylamide gel. Supershift experiments were performed at time points when a new complex appeared as indicated. Complex formation for supershift experiments was performed with antibodies directed against STAT1, STAT2, STAT3, STAT4, and STAT5b purchased from Santa Cruz Biotechnology, Inc.

Immunofluorescence. For immunofluorescence experiments, cryosections (4-5 $\mu \mathrm{m}$ thick) were prepared and fixed immediately for 5 min in ice-cold acetone, air dried, and either stored at $-80^{\circ} \mathrm{C}$ or used immediately. Immunofluorescence staining was performed essentially as described previously (21). Anti-STAT3 (Santa Cruz Biotechnology, Inc.) and anticytochrome P450 2D6 were both incubated as primary antibodies. As secondary antibodies, anti-rabbit IgG Cy3conjugated (Sigma Chemical Co., St. Louis, MO) and anti-human FITC-conjugated (Dianova GmbH, Hamburg, FRG) were used. Sections were analyzed through either a $615-\mathrm{nm}$ filter (Cy3 staining) or a 525-nm filter (FITC staining) with a fluorescence microscope (Olympus, Hamburg, Germany).

Northern blot analysis. Northern blot analysis was performed according to standard procedures (18). Total RNA was isolated by the guanidium isothiocyanate method. $20 \mu \mathrm{g}$ of total RNA was analyzed through a $1 \%$ agarose formaldehyde gel, followed by transfer to Hybond $\mathrm{N}^{+}$membranes (Amersham Buchler $\mathrm{GmbH}$ ). The C/EBP- $\beta$ / LAP and GAPDH cDNA probes were labeled with $\left[\alpha{ }^{32} \mathrm{P}\right] \mathrm{ATP}$ according to random priming (Boehringer Mannheim, Mannheim, Germany). The hybridization procedure was performed as described previously (18).

DNA fragmentation. To determine DNA fragmentation by ELISA, one liver lobe $(20 \%)$ was treated in TE buffer with five strokes of a homogenizer (pestle B). The $20 \%$ homogenate was centrifuged at $13,000 \mathrm{~g}$ for $20 \mathrm{~min}$.

For semiquantitative determination of DNA fragmentation, the pattern of low weight DNA was analyzed on an agarose gel. The DNA was precipitated from the supernatant by addition of $\mathrm{NaCl}(5$ $\mathrm{mol} /$ liter)/ethanol, extracted by phenol/chloroform, and again precipitated in ethanol. Subsequently, electrophoresis on a $1 \%$ agarose gel and ethidium bromide staining were performed. The nx123-bp molecular weight marker used for gel electrophoresis was from GIBCO (Eggenstein, Germany).

After centrifugation, the supernatant of the $20 \%$ homogenate was diluted further 200-fold and used directly to determine DNA fragmentation by the commercially available ELISA system cell death detection kit (Boehringer Mannheim) according to the manufacturer's instructions, designed to quantify cytosolic oligonucleosome-bound DNA (histone ELISA).

5-Bromo-2'-deoxyuridine (BrdU) labeling. For in vivo labeling, $30 \mu \mathrm{g} / \mathrm{g}$ of mouse of BrdU (Amersham Buchler $\mathrm{GmbH}$ ) was injected intraperitoneally $2 \mathrm{~h}$ before killing. Liver tissue was frozen immediately in liquid nitrogen. To detect labeled nuclei, cryosections were prepared ( $5 \mu \mathrm{m}$ thick). The tissue was fixed in ice-cold acetone/methanol, and staining was performed according to a cell proliferation kit (Amersham Buchler GmbH).

Quantification. Quantification of results was performed with an 
imager (Fuji Photo Film Co., Tokyo, Japan) or by a densitometer as described previously (18).

\section{Results}

Con A injection leads to liver injury. Con A injection leads to $\mathrm{T}$ cell activation and recruitment of mononuclear cells into the liver, resulting in apoptosis of hepatocytes $(3,22)$. To monitor the time course of liver cell injury, aminotransferase levels were measured in the serum after Con A injection (Fig. 1 A). Aminotransferases increased as early as $4 \mathrm{~h}$ after Con A injection and showed maximum serum levels at the 8-24-h time points. After $24 \mathrm{~h}$, the aminotransferase levels decreased again, and compared with pretreatment levels, no significant change was found $96 \mathrm{~h}$ after Con A injection. After injection of the buffer control, no change in aminotransferases was observed (Fig. $1 A$ ). After performing anti-TNF blocking experiments, the rise in aminotransferase levels was reduced significantly. However, compared with mice treated with buffer control alone, a rise in aminotransaminases was still evident (Fig. 1A).

To investigate whether the rise in aminotransferases is associated with apoptosis in the liver, DNA fragmentation was measured. $8 \mathrm{~h}$ after injection of either the buffer control, Con A alone, or Con A in combination with anti-TNF, DNA fragmentation was assessed semiquantitatively from whole liver tissue on an agarose gel. As shown in Fig. $1 B$, anti-TNF treat-

\section{A}

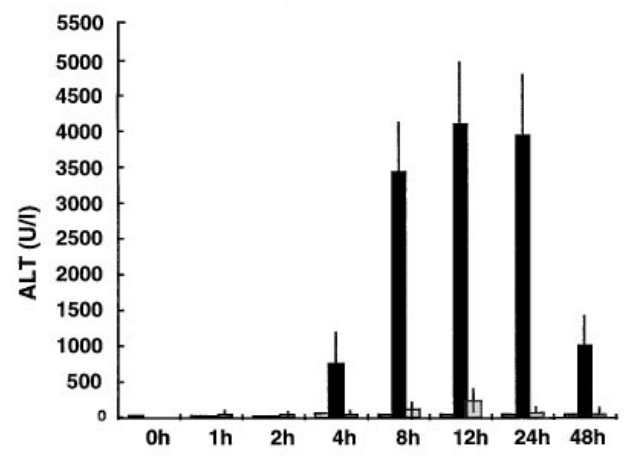

D
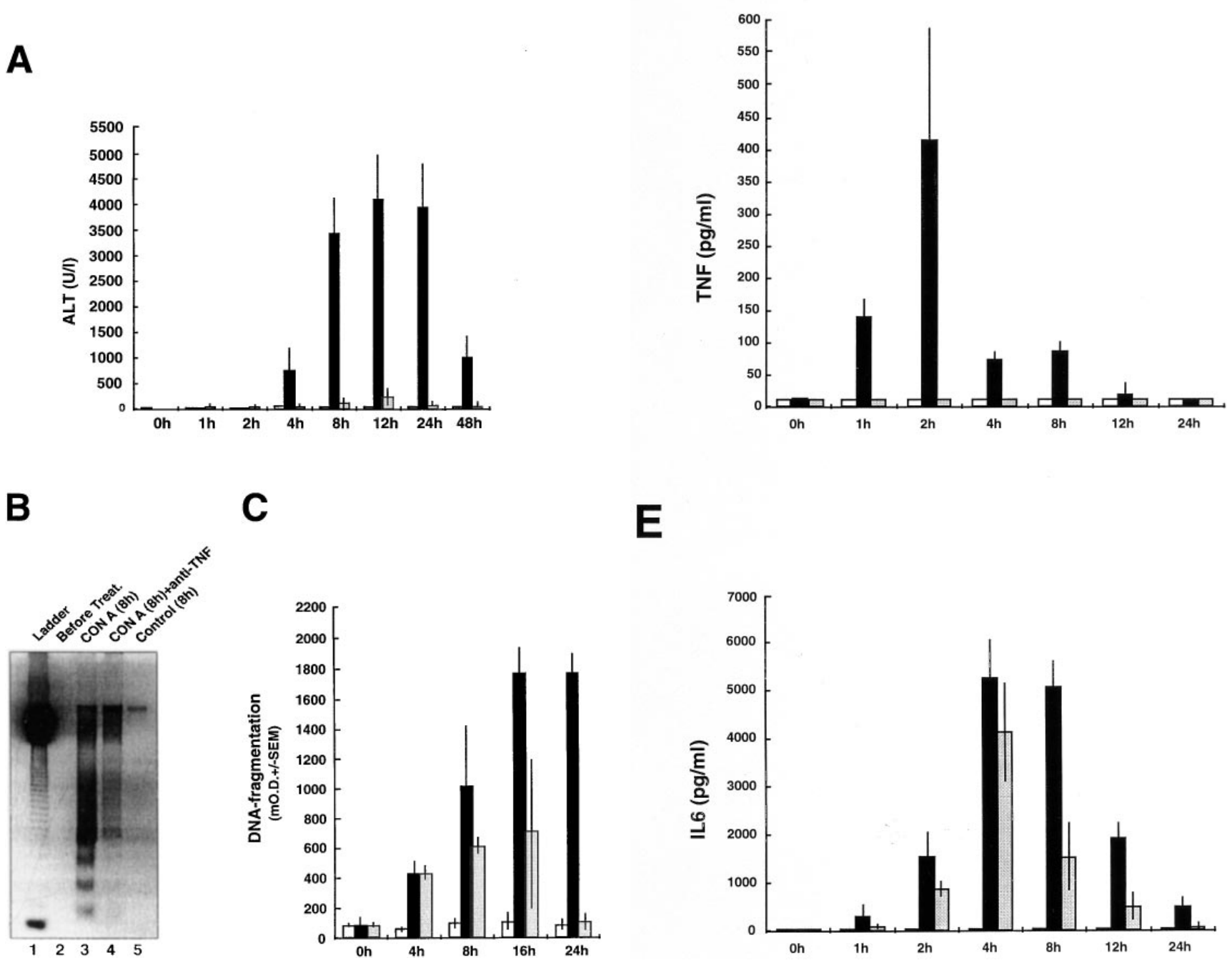

Figure 1. Con A injection induces changes in the serum level of aminotransferases and cytokines. Changes in the serum levels of aminotransferases $(A)$, DNA fragmentation $(B$ and $C)$, TNF- $\alpha(D)$, and IL-6 $(E)$ were monitored before and after injection of either Con A (black bars), the buffer control (white bars), or Con A and anti-TNF (gray bars). Apoptosis in the liver was measured by semiquantitative determination of DNA fragmentation on an agarose gel $(B)$. In lane 1, the 123-bp DNA ladder is shown, and in lane 2, DNA fragmentation before treatment is shown. In lanes 3-5, the three different conditions (3, Con A; 4, Con A and anti-TNF; 5, buffer control) are shown $8 \mathrm{~h}$ after injection. In $C$ quantification of apoptosis was performed using the death detection ELISA kit at the time points indicated. The level of each value is indicated after injection. Aminotransferases $(A L T)$ are given in U/liter, DNA fragmentation in OD, and the cytokines are given in $\mathrm{pg} / \mathrm{ml}$. 
ment reduced DNA fragmentation. This result was further quantitated by histone ELISA (Fig. $1 C$ ). As in the time course experiments, DNA fragmentation was reduced significantly when anti-TNF was administered before Con A injection.

IL- 6 and TNF- $\alpha$ plasma levels were measured after Con A, Con A plus anti-TNF, and buffer control injection (Fig. 1, D and $E$ ). Plasma TNF- $\alpha$ levels peaked as early as $2 \mathrm{~h}$ after Con A injection and decreased thereafter, and pretreatment levels were reached again after $24 \mathrm{~h}$ (Fig. $1 \mathrm{D}$ ). The TNF- $\alpha$ plasma levels remained unchanged in control-treated animals and after anti-TNF treatment (Fig. $1 D$ ).

After Con A injection, maximum IL-6 levels were found after the rise in TNF plasma levels. Peak IL-6 levels were measured 4-8 h after Con A injection, and pretreatment levels were found after $48 \mathrm{~h}$ (Fig. $1 \mathrm{E}$ ). No changes in IL-6 levels were found after injection of the buffer control. After antiTNF plus Con A treatment, IL-6 levels were reduced compared with Con A alone. However, the reduction was less clear than found for aminotransferase levels.

Con A-dependent liver injury induces hepatocyte proliferation. Con A-induced liver injury and peak plasma levels of cytokines, also involved in triggering the transition of hepatocytes into the cell cycle, were most evident during the first $24 \mathrm{~h}$ after Con A injection. Therefore, we studied whether these events may induce hepatocyte proliferation. The nuclear expression of cyclin A-a marker of the S-phase of the cell cycle (23) - was studied by Western blot analysis of nuclear extracts. $24 \mathrm{~h}$ after Con A injection, cyclin A was detected in the nucleus of hepatocytes, and the maximal expression of cyclin A was evident $48 \mathrm{~h}$ after Con A injection (Fig. 2). Cyclin A levels remained high for up to $96 \mathrm{~h}$. After $168 \mathrm{~h}$, nuclear cyclin A expression decreased again. In control-treated animals, nuclear cyclin A expression remained undetectable at the time points studied (data not shown).

To further elucidate cell cycle progression after Con A injection, BrdU labeling was performed before and at different time points after injection (Fig. 3). In Fig. $3 A$, BrdU staining is shown before injection, and Fig. 3, $B-D$, depicts the livers of all three conditions (Con A, Con A plus anti-TNF, and buffer control) $48 \mathrm{~h}$ after injection. At the time point $48 \mathrm{~h}$ after Con

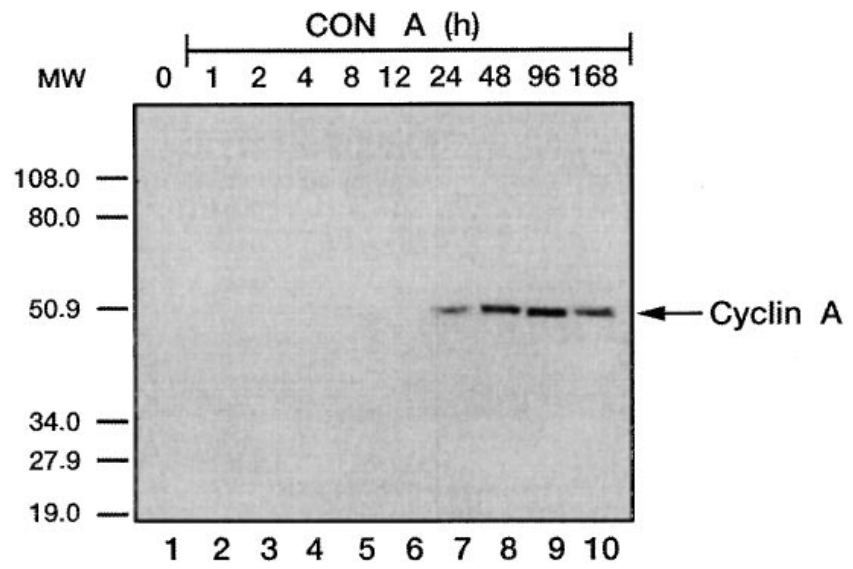

Figure 2. Con A injection induces nuclear expression of cyclin A. In mice treated with Con A, nuclear extracts were prepared before and at different time points after injection as indicated. Western blot analysis was performed with an anti-cyclin A antibody.
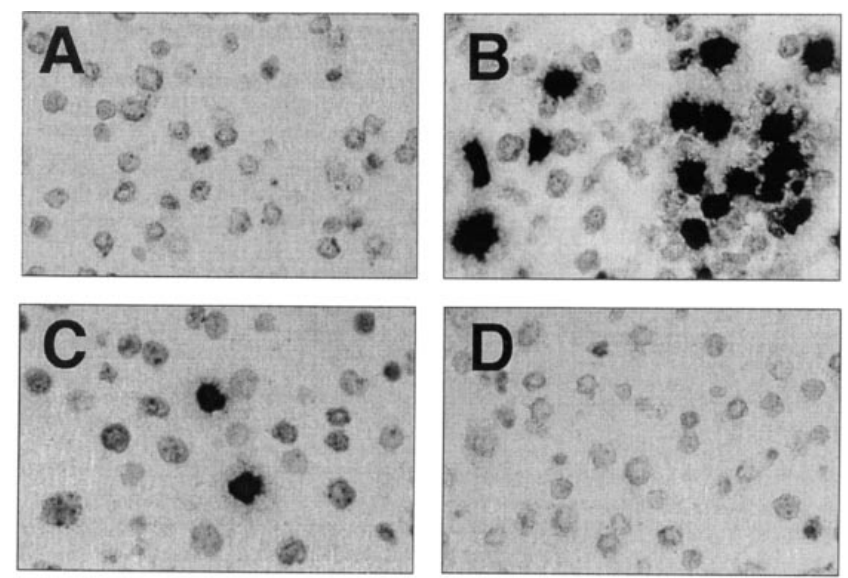

E

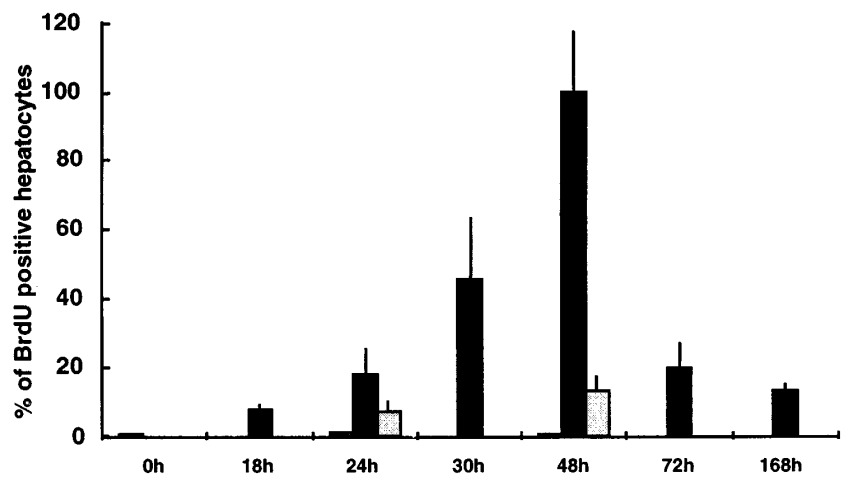

Figure 3. DNA synthesis after Con A injection. BrdU labeling of hepatocyte nuclei was measured before $(A)$ and $48 \mathrm{~h}$ after injection of Con A $(B)$, Con A and anti-TNF $(C)$, and buffer control $(D)$. In $E$, the BrdU-positive nuclei $48 \mathrm{~h}$ after Con A injection were set to $100 \%$, and the relative percentage at the different time points is shown for the three conditions (Con A [black bars], Con A and anti-TNF [gray bars], and buffer control [white bars]).

A injection, the maximum level of positive nuclei was found $356 \pm 48 / 1,000$ cells were positive. To monitor the relative changes after Con A injection in Fig. $3 \mathrm{E}$, the time point $48 \mathrm{~h}$ after Con A injection was set to $100 \%$. After Con A injection, an increase in positive nuclei was first detected $24 \mathrm{~h}$ after Con A injection, and after $168 \mathrm{~h},<10 \%$ of the cells were positive compared with $48 \mathrm{~h}$ after Con A injection. After Con A and anti-TNF treatment, the number of positive nuclei was reduced significantly compared with Con A alone.

$C / E B P-\beta / L A P$ expression increases before start of DNA synthesis. Con A injection leads to elevated TNF- $\alpha$ plasma levels and apoptosis. In addition to its role in the induction of apoptosis in hepatocytes, it has also been suggested that TNF may control nuclear C/EBP- $\beta / L A P$ expression during liver regeneration and thus contribute to hepatocyte proliferation (11, 17). Therefore, we investigated mRNA expression of C/EBP$\beta / \mathrm{LAP}$ at different time points after Con $\mathrm{A}$ injection and performed blocking experiments with anti-TNF antibodies.

After Con A treatment, a slight increase in the mRNA ex- 


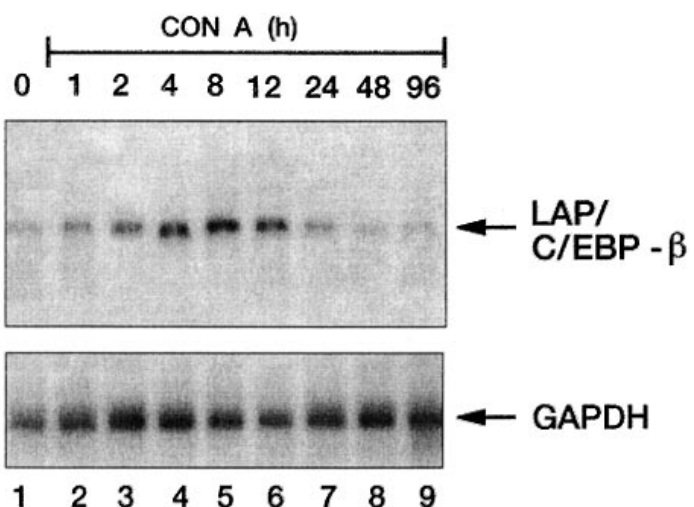

B

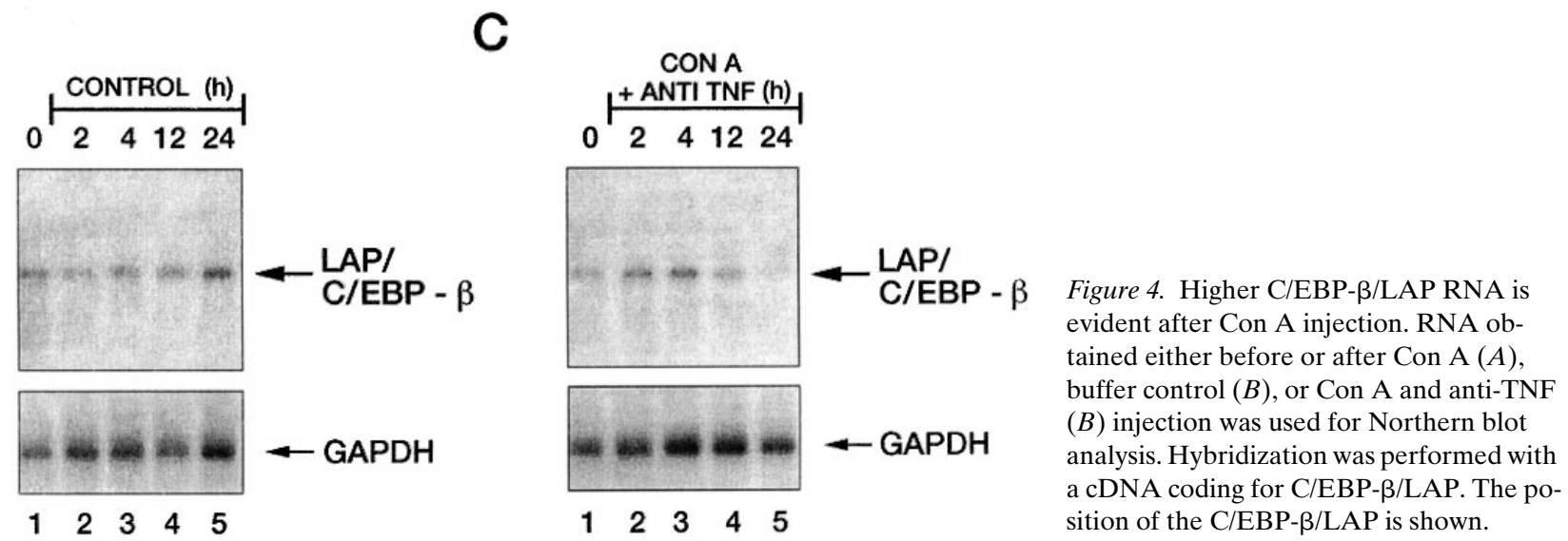

pression of C/EBP- $\beta /$ LAP was already evident $1 \mathrm{~h}$ after Con A injection (more than twofold), and a further increase was found (maximal eightfold) 4-12 h after administration (Fig. 4 A). Pretreatment levels were found again $48 \mathrm{~h}$ after Con A injection. In control-treated animals, no significant change in C/EBP- $\beta$ /LAP was evident (Fig. 4 B). When anti-TNF was administered together with $\mathrm{Con} A$, there was a slight increase (2.5-fold) in C/EBP- $\beta / L A P$ mRNA expression 2-12 $\mathrm{h}$ after injection. However, the second increase as observed after Con A injection alone was not found (Fig. $4 C$ ).

Expression and activity of C/EBP- $\beta / \mathrm{LAP}$ is also controlled on the posttranslational level $(20,24)$. Thus, we studied the nuclear expression of C/EBP- $\beta / L A P$ in liver nuclear extracts by Western blot analysis. Already $1 \mathrm{~h}$ after Con A injection, there was an increase in the nuclear expression of C/EBP- $\beta / L A P$, whereas there was no significant regulation in animals treated with buffer control or Con A and anti-TNF (Fig. 5, $A-C$ ). At later time points $-4-8 \mathrm{~h}$ after Con A injection-maximum nuclear expression of C/EBP- $\beta / L A P$ was found. Starting $12 \mathrm{~h}$ after Con A injection, nuclear expression of C/EBP- $\beta / L A P$ decreased again, and pretreatment levels were found at later time points. To check quality and quantity of the nuclear proteins, Coomassie staining of the SDS gels was performed (data not shown).

In addition to $\mathrm{C} / \mathrm{EBP}-\beta / \mathrm{LAP}$, nuclear expression of $\mathrm{C} / \mathrm{EBP}-\alpha$ was monitored. In contrast to the higher expression of $\mathrm{C} / \mathrm{EBP}-\beta /$
LAP, there was no significant change in the expression of $\mathrm{C} / \mathrm{EBP}-\alpha$ after Con A injection (data not shown).

The DNA binding activity of C/EBP- $\beta / L A P$ can be controlled through an inhibitory domain in close proximity to the basic domain (25). Therefore, gel shift experiments with the D site of the albumin were performed to analyze whether the changes found in nuclear C/EBP- $\beta /$ LAP protein expression correspond to its DNA binding activity. $1 \mathrm{~h}$ after Con A injection, and more pronounced after $2 \mathrm{~h}$, there was an increase in the intensity of three bands. Maximum intensity was found up to $8 \mathrm{~h}$. Pretreatment DNA binding was evident again after $48 \mathrm{~h}$. Supershift experiments were performed with the nuclear extracts $8 \mathrm{~h}$ after Con $\mathrm{A}$ injection and recombinant $\mathrm{C} / \mathrm{EBP}-\beta /$ LAP. As shown in Fig. $6 A$, lanes 4 and 5 , all complexes with increased intensity in the time course experiments were supershifted with anti-C/EBP- $\beta / L A P$. A very similar pattern was found when recombinant C/EBP- $\beta / \mathrm{LAP}$ was used (Fig. 6, lanes 2 and 3). No significant changes in binding pattern versus the $\mathrm{D}$ site of the albumin promoter were found after injection of either Con A and anti-TNF or the buffer control (Fig. $6 B$ ).

Increased nuclear expression and DNA binding of STAT3/ $A P R F$ before entry of hepatocytes into the $S$-phase of the cell cycle. Recent experiments suggested that IL- 6 and thus activation of STAT3/APRF plays a critical role in liver regeneration after two-thirds hepatectomy (10). As Con A-induced liver injury leads to hepatocyte proliferation, we studied the nuclear 
A

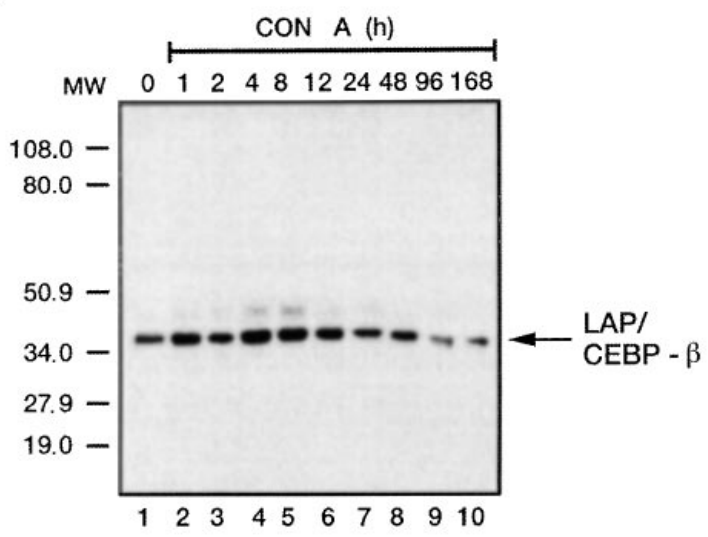

B

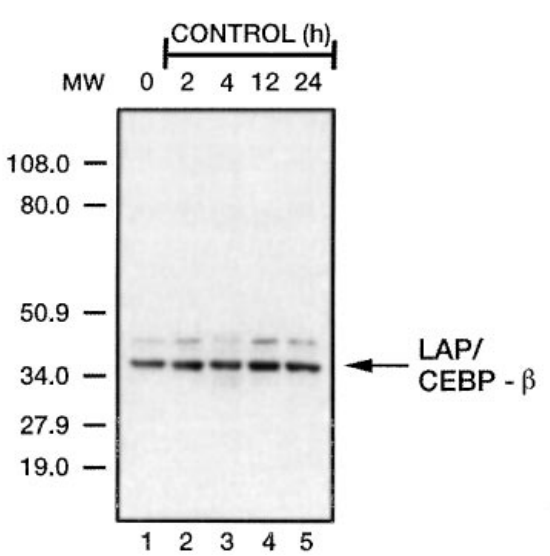

C

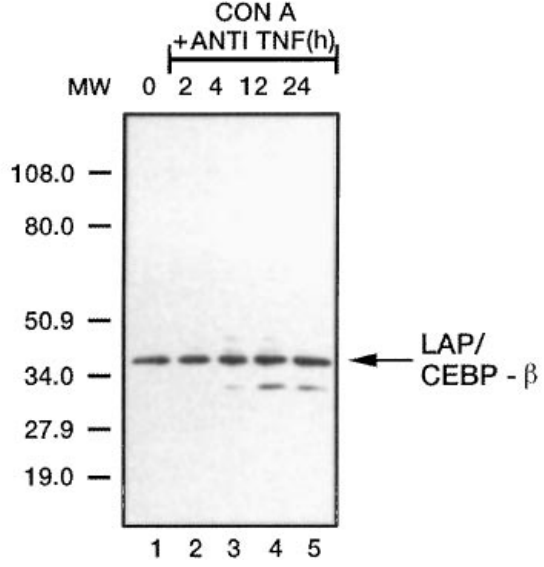

Figure 5. Higher nuclear expression of $\mathrm{C} / \mathrm{EBP}-\beta / \mathrm{LAP}$ after Con A injection is mediated by TNF- $\alpha$. Nuclear extracts were prepared before and after injection of Con A $(A)$, the buffer control $(B)$, and Con A and anti-TNF $(C)$. Western blot analysis was performed with an anti-C/EBP- $\beta / \mathrm{LAP}$ antibody. expression of APRF/STAT3 by Western blot analysis. An increase in nuclear STAT3/APRF protein was already evident after $1 \mathrm{~h}$, and maximum regulation was observed at the 2 - and 4-h time points. At later time points, the nuclear expression of
STAT3/APRF decreased again and returned to pretreatment level at $48 \mathrm{~h}$ after administration of Con A (Fig. $7 A$ ). The increase in nuclear expression of STAT3/APRF was not evident in control-treated animals (Fig. $7 \mathrm{~B}$ ).
A

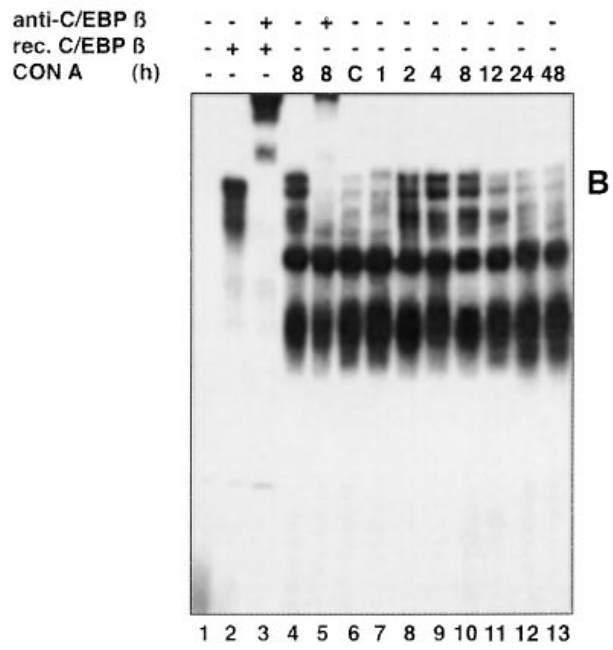

B

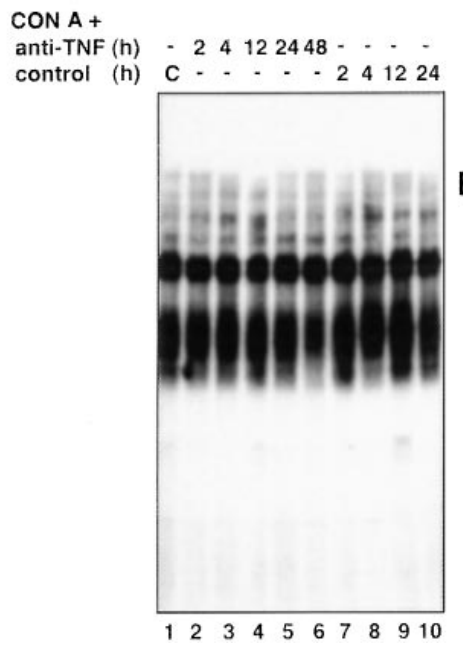

Figure 6. DNA binding of C/EBP-B/LAP. Gel shift experiments were performed usB ing an oligonucleotide spanning the $\mathrm{D}$ site of the albumin promoter. The oligonucleotide was incubated with either recombinant $\mathrm{C} / \mathrm{EBP}-\beta / \mathrm{LAP}$ or liver nuclear extracts. Liver nuclear extracts were prepared before or after Con $\mathrm{A}(A)$, Con A and anti-TNF, or buffer control injection (B). As shown in $A$, supershift experiments were performed with liver nuclear extracts $8 \mathrm{~h}$ after Con $\mathrm{A}$ injection and with recombinant C/EBP- $\beta / L A P$. An anti-C/EBP-

$\beta /$ LAP antibody was used for supershift experiments. $C$, Liver nuclear extracts before treatment. 
A

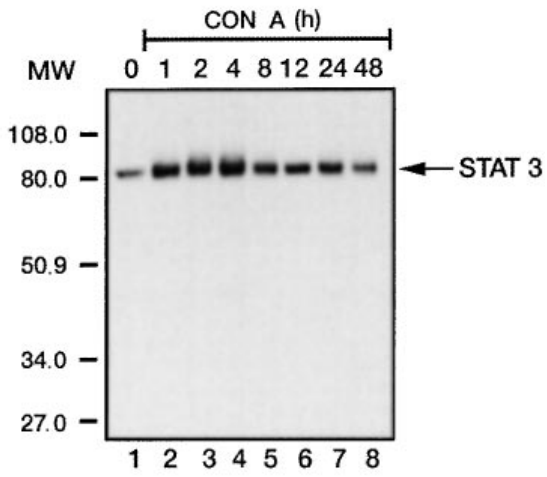

B

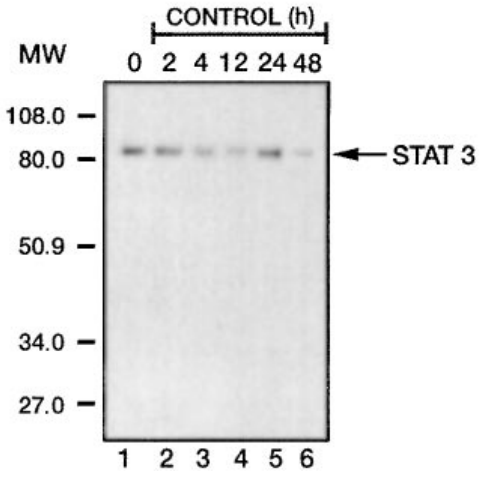

Figure 7. Con A injection induces an increase in the nuclear expression of STAT3. Nuclear extracts were prepared before and after injection of Con $\mathrm{A}(A)$ and the buffer control $(B)$. Western blot analysis was performed with an anti-STAT3 antibody.

After Con A injection, immune-activated cells infiltrate the liver $(2,4)$. STAT3/APRF is expressed in several cell types. To determine the cells where STAT3/APRF is present in the nucleus, double immunofluorescence studies on liver slides were performed with anti-STAT3 and anti-P450 2D6. Cytochrome P450 2D6 is a hepatocyte-specific microsomal enzyme. As depicted in Fig. $8 B, 4 \mathrm{~h}$ after Con A injection, STAT3/APRF was specifically detected in the nucleus of hepatocytes. There was no nuclear expression of STAT3/APRF in the liver of either untreated animals, animals after injection of the buffer control, or animals at time points later than $24 \mathrm{~h}$ after Con A was administered. Thus, immunofluorescence demonstrated that the STAT3/APRF protein is located in the nucleus of hepatocytes, and no zonal distribution was found in the liver of animals treated with Con A.

As Con A injection leads to an increase in the nuclear translocation of STAT3/APRF, we used gel shift experiments to determine whether this event is associated with increased DNA binding. $1 \mathrm{~h}$ after Con A injection, specific complex formation was found when nuclear extracts were incubated with a ${ }^{32} \mathrm{P}$-labeled oligo representing a STAT3/APRF binding site (Fig. 9 A). This specific complex was composed of three bands. After $2 \mathrm{~h}$, an additional slow migrating complex did appear. A continuous increase in intensity of all four complexes was obvious for up to $8 \mathrm{~h}$ after Con A treatment. At the 12-h time point, the intensity of all complexes decreased dramatically. After $24-48 \mathrm{~h}$, the intensity of the bands was comparable to the pretreatment level. After injection of the buffer control, no new complex formation was detected (Fig. $8 \mathrm{~B}$ ).

The consensus DNA binding site of the different STAT proteins shows little variation (26). Therefore, supershift experiments with antibodies directed against different STAT family members were performed (Fig. $9 C$, and data not shown) using nuclear extracts $4 \mathrm{~h}$ after Con A injection. Only antiSTAT1 and anti-STAT3/APRF lead to a supershift of distinct bands. As shown in Fig. $9 C$, anti-STAT3/APRF supershifted completely the upper two of the four bands, and anti-STAT1 supershifted both lower bands. A combination of both antibodies (anti-STAT1 and anti-STAT3/APRF) supershifted all four bands. Thus, all four new bands which specifically appeared after Con A injection either contain STAT1 or STAT3/ APRF as homo- or heterodimers.

\section{Discussion}

Con A injection leads to infiltration of the liver by immuneactivated cells. This results in the release of several cytokines triggering liver damage. TNF- $\alpha$ and IFN- $\gamma$ are particularly involved in this process. Liver injury through Con A is a dosedependent process during which at lower concentrations after the initial damage, the liver function is reconstituted $(2-4,9)$. However, the molecular mechanisms involved in this process are unknown.

In this study, we show that after Con A injection and the initial increase in aminotransferase levels induced by apoptosis, the remaining hepatocytes enter the cell cycle. Cyclin A expression and BrdU labeling can be detected in the nucleus of hepatocytes already $24 \mathrm{~h}$ after Con A injection. These results indicate that cytokines like TNF- $\alpha$ and IL- 6 secreted after Con A injection may also be involved in the induction of cell proliferation of hepatocytes. Therefore, we analyzed the molecular mechanisms controlled by IL- 6 and TNF- $\alpha$ known to mediate the entry of hepatocytes into the cell cycle $(10,11,17,27)$.

Earlier results indicated that high $\mathrm{C} / \mathrm{EBP}-\beta / \mathrm{LAP}$ protein levels block cell cycle progression at the G1/S-phase checkpoint and thus prevent cells from entering the S-phase of the cell cycle $(28,29)$. The nuclear expression of C/EBP- $\beta / L A P$ increases for up to $4 \mathrm{~h}$ after Con A injection and remains elevated for up to $12 \mathrm{~h}$. After $24 \mathrm{~h}$, hepatocytes enter the S-phase of the cell cycle, which was verified by cyclin A and BrdU labeling. At this time point, nuclear protein expression of $\mathrm{C} / \mathrm{EBP}$ $\beta /$ LAP has already returned to normal. These experiments clearly show that-consistent with experimental results obtained after two-thirds hepatectomy-also after Con A injection, C/EBP- $\beta / \mathrm{LAP}$ is upregulated during this transition phase. Further experiments are necessary to show that the upregulation of $\mathrm{C} / \mathrm{EBP}-\beta / \mathrm{LAP}$ at this time point is essential to trigger the resting hepatocyte from G0-phase into the cell cycle. However, when DNA synthesis starts, its nuclear expression is back to normal-possibly because high nuclear C/EBP$\beta /$ LAP expression at this stage of the cell cycle would prevent hepatocytes from cell proliferation.

The increase in mRNA and protein expression was reduced significantly when the animals were treated with Con A and anti-TNF antibodies compared with Con A injection alone. These results indicate that TNF-dependent signals may control C/EBP- $\beta / \mathrm{LAP}$ expression on the mRNA and protein 

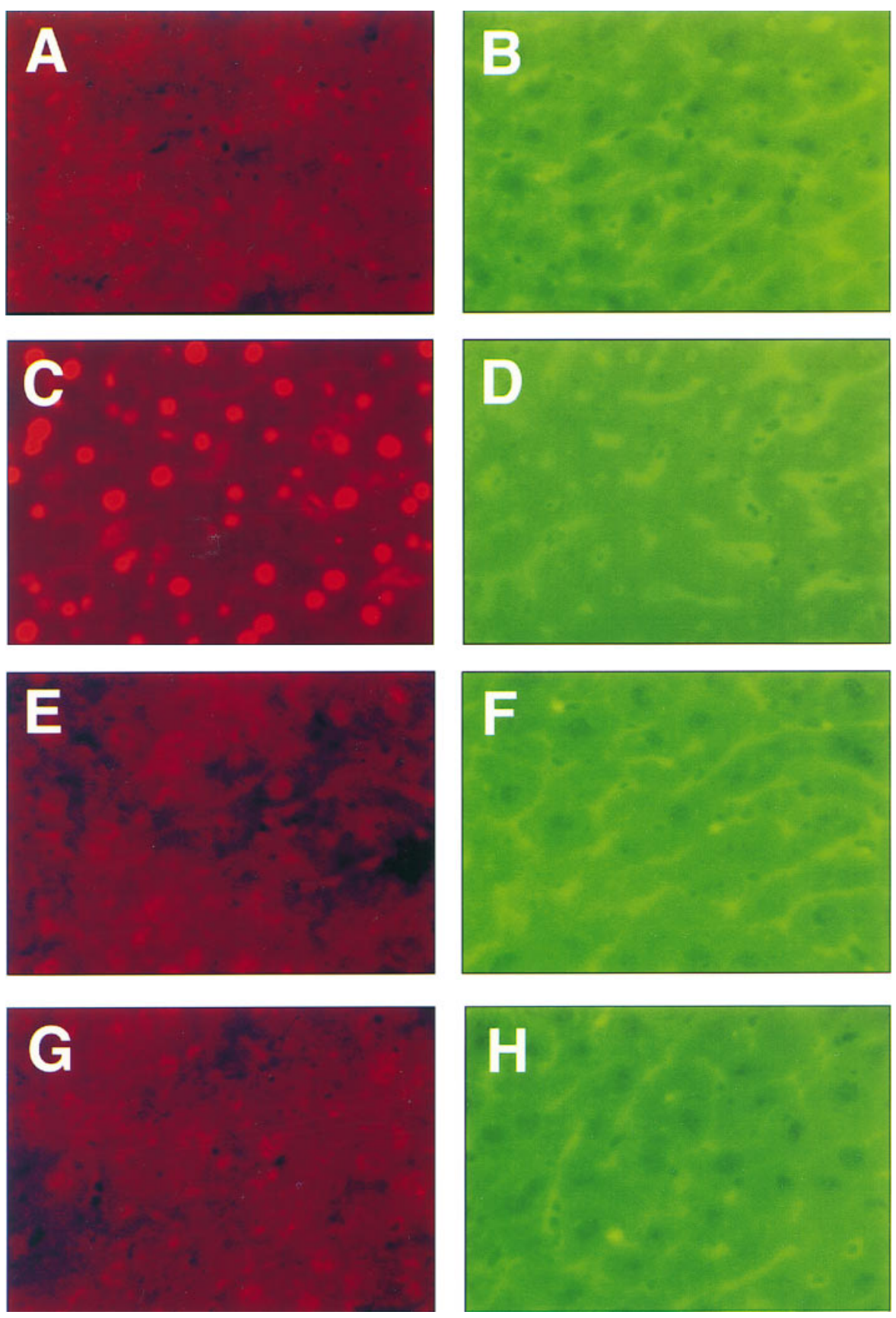

Figure 8. Higher nuclear STAT3 expression was found in hepatocytes after Con A injection. Liver sections were stained by double immunfluorescence with antibodies directed against STAT3 (red) $(A, C, E$, and $G$ ) and cytochrome P450 2D6 (green) $(B, D, F$, and $H$ ) expression. Samples are shown before treatment $(A$ and $B), 4(C$ and $D$ ) and $24(E$ and $F)$ h after Con $\mathrm{A}$ injection, and $4 \mathrm{~h}$ after administration of the buffer control ( $G$ and $H$ ). level. One of the mechanisms leading to higher C/EBP- $\beta / \mathrm{LAP}$ expression is an increase in its nuclear translocation triggered by TNF- $\alpha$ (30). The increase in C/EBP- $\beta /$ LAP nuclear protein expression observed at later time points (4-8 h after Con A injection) is more likely a consequence of the increase observed on the mRNA level. The intracellular signaling pathway promoting C/EBP- $\beta / \mathrm{LAP}$ nuclear translocation in a TNF-dependent fashion is unknown.

The pathways originating at the intracellular domain of the TNF receptor are essential to induce either apoptosis or cell proliferation in hepatocytes $(11,17,31-33)$. However, activation of the TNF receptor alone seems insufficient to trigger either condition. Additional signals are required. IFN- $\gamma$ is an es- sential costimulatory signal in the induction of TNF-dependent apoptosis after Con A injection, as anti-IFN treatment before Con A injection prevents apoptosis (9).

In contrast to IFN- $\gamma$, IL- 6 has a different costimulatory effect on TNF-dependent signaling. IL-6 pretreatment before Con $\mathrm{A}$ injection prevents liver injury and thus has a protective role in the process of TNF-dependent apoptosis (4). To investigate the IL-6-dependent mechanisms after Con A injection, nuclear expression of STAT3/APRF was studied. IL-6 induces tyrosine phosphorylation of STAT3/APRF, which leads to the nuclear translocation of STAT3/APRF and activation of its target genes $(13,34)$. Nuclear translocation of STAT3/APRF was found early after Con A injection. In contrast, there was a 
A

B
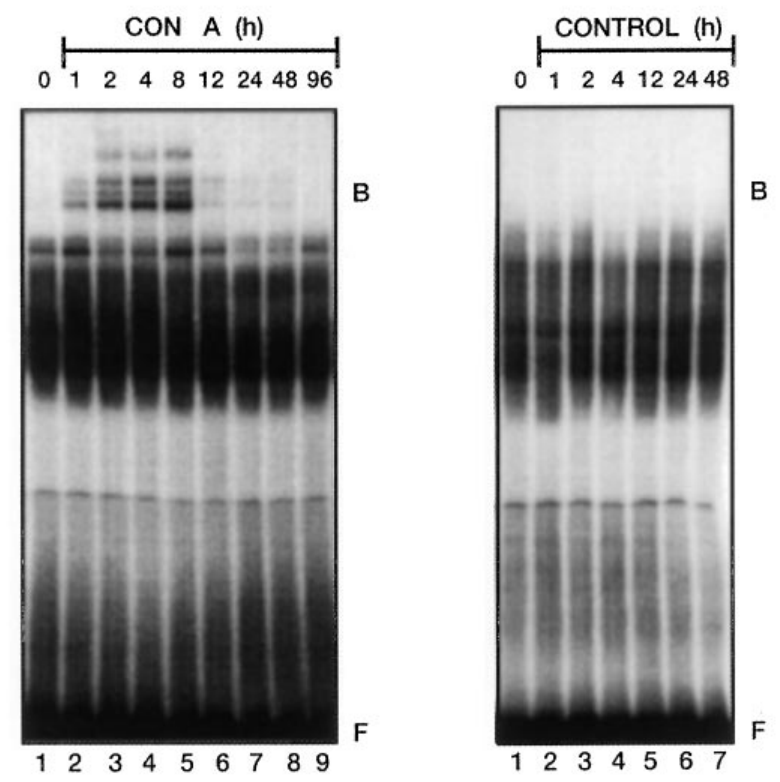

C

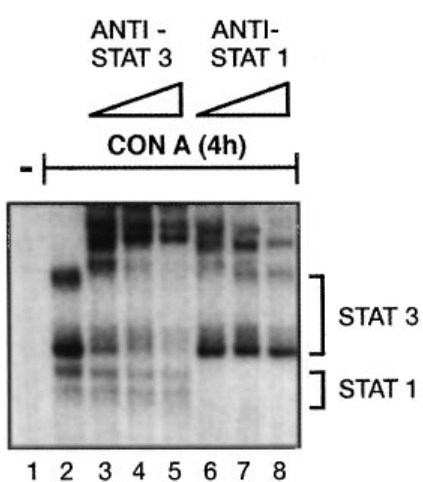

found in the two knockout mice after partial hepatectomy. The lack in IL-6 plasma levels was associated with impaired DNA synthesis, and no nuclear translocation of STAT3/APRF was found $(10,27)$. After Con A injection, elevated IL-6 plasma levels were also evident before the start of DNA synthesis. From this, one can conclude that IL- 6 might be essential to trigger proliferation of hepatocytes in this new model of $\mathrm{T}$ cell-induced liver damage and regeneration. In contrast to the TNF receptor 1 knockout mice, where no increase in IL-6 was found after hepatectomy, anti-TNF pretreatment did not block the rise in IL-6 serum levels after Con A injection. Two things may account for this observation. First, several cytokines are elevated after Con A injection, and therefore, additional cytokines may contribute to the elevation of IL-6 serum levels. Second, after Con A injection, high serum TNF- $\alpha$ levels were found, and anti-TNF pretreatment totally blocks TNF serum levels. However, the block in liver tissue might not be complete, and a small amount of TNF may be released locally which induces IL-6 expression.

From these data, a sequential model of TNF-regulated hepatocyte damage-apoptosis and necrosis-and proliferation after Con $\mathrm{A}$ injection can be deduced. After an initial period of liver damage induced by the cooperative action of TNF- $\alpha$ and IFN- $\gamma$, entry of hepatocytes into the cell cycle can be observed. The regenerative phase is in turn regulated by the secretion of IL- 6 . Whereas TNF leads to the induction of C/EBP- $\beta /$ LAP during the transition phase between $\mathrm{G} 0$ and $\mathrm{S}$, in which hepatocytes prepare for cell cycle progression, IL-6 by inducing STAT3/APRF might - besides contributing to cell proliferation-also induce antiapoptotic signals which inhibit further liver damage (35).

IL-6 and IFN both act during two different periods of Con A-induced liver injury: IFN in the apoptotic and IL-6 during the regenerative phase. Earlier results showed that IFN via STAT1 has an antiproliferative effect, whereas IL-6 via STAT3 is required for hepatocyte proliferation $(10,27,36)$. Both STAT1 and STAT3/APRF bind DNA at a very similar consensus motif (24). Activation of STAT1 and STAT3 at their specific receptors is triggered by the family of Janus kinases (37). Thus, even IFN- and IL-6-dependent signaling are closely related. These pathways seem to modulate TNF-dependent signaling in different directions after Con A injection.

In summary, this study demonstrates that Con A injection leads to apoptosis and hepatocyte proliferation. TNF controls nuclear C/EBP- $\beta$ /LAP expression, and IL-6 activates STAT3/ APRF. Both events are found before the start of DNA replication. Further experiments in the Con A model which interfere with the cytokine-dependent signaling cascades will help to understand the molecular mechanisms necessary to trigger either TNF-dependent apoptosis or cell proliferation of hepatocytes in vivo. As similar immune-mediated mechanisms are important in autoimmune and viral hepatitis, these results are also relevant for the pathogenesis of liver injury in humans. Therefore, further investigations in this unique model may have implications for the development of new treatment options.

\section{Acknowledgments}

We thank G. Draetta for the cyclin A, and E. Ziff for the C/EBP$\beta /$ LAP antibody.

This work was supported by the Deutsche Forschungsgemeinschaft, grant $\operatorname{Tr} 285$ 3-2. 


\section{References}

1. Diehl, A.M., and R.M. Rai. 1996. Regulation of signal transduction during liver regeneration. FASEB (Fed. Am. Soc. Exp. Biol.) J. 10:215-227.

2. Tiegs, G., J. Hentschel, and A. Wendel. 1992. A T cell-dependent experimental liver injury in mice inducible by concanavalin A. J. Clin. Invest. 90:196-203.

3. Gantner, F., M. Leist, A.W. Lohse, P.G. Germann, and A. Tiegs. 1995. Concanavalin A-induced T-cell-mediated hepatic injury in mice: the role of tumor necrosis factor. Hepatology. 21:190-198.

4. Mizuhara, H., E. O’Neill, N. Seki, T. Ogawa, C. Kusunoki, K. Otsuka, S. Satoh, M. Niwa, H. Senoh, and H. Fujiwara. 1994. T-cell activation-associated hepatic injury: mediation by tumor necrosis factor and protection by interleukin 6. J. Exp. Med. 179:1529-1537.

5. Löhr, H.F., J. Schlaak, A.W. Lohse, W.O. Böcher, M. Arenz, G. Gerken, and K.-H. Meyer zum Büschenfelde. 1996. Autoreactive CD4 ${ }^{+}$LKM-specific and anticlonotypic T-cell responses in LKM-1 antibody-positive autoimmune hepatitis. Hepatology. 24:1416-1421.

6. Ferrari, C., M.U. Mondelli, A. Penna, F. Fiaccadori, and F.V. Chisari. 1987. Functional characterization of cloned intrahepatic, hepatitis B virus nucleoprotein-specific helper T cell lines. J. Immunol. 139:539-544.

7. Löhr, H.F., W. Weber, J. Schlaak, B. Goergen, K.-H. Meyer zum Büschenfelde, and G. Gerken. 1995. Proliferative response of CD4 ${ }^{+}$T cells and hepatitis B virus clearance in chronic hepatitis with or without hepatitis B e-minus virus mutants. Hepatology. 22:61-68.

8. Napoli, J., G.A. Bishop, P.H. McGuiness, D.M. Painter, and G.W. McCaughan. 1996. Progressive liver injury in chronic hepatitis $\mathrm{C}$ infection correlates with increased intrahepatic expression of Th1-associated cytokines. Hepatology. 24:759-765.

9. Küsters, S., F. Gantner, G. Künstle, and G. Tiegs. 1996. Interferon gamma plays a critical role in $\mathrm{T}$ cell-dependent liver injury in mice initiated by concanavalin A. Gastroenterology. 111:462-471.

10. Cressman, D.E., L.E. Greenbaum, R.A. DeAngelis, G. Ciliberto, E.E. Furth, V. Poli, and R. Taub. 1996. Liver failure and defective hepatocyte regeneration in interleukin-6-deficient mice. Science. 274:1379-1383.

11. Akerman, P.A., P. Cote, S.Q. Yang, C. McClain, S. Nelson, G.J. Bagby, and A.M. Diehl. 1992. Antibodies to tumor necrosis factor- $\alpha$ inhibit liver regeneration after partial hepatectomy. Am. J. Physiol. 263:G579-G585.

12. Akira, S., Y. Nishio, M. Inoue, X.-J. Wang, S. Wei, T. Matsusaka, K. Yoshida, T. Sudo, M. Naruto, and T. Kishimoto. 1994. Molecular cloning of APRF, a novel IFN-stimulated gene factor 3 p91-related transcription factor involved in the gp130-mediated signaling pathway. Cell. 77:63-71.

13. Zhong, Z., Z. Wen, and J.E. Darnell. 1994. Stat3: a Stat family member activated by tyrosine phosphorylation in response to epidermal growth factor and interleukin-6. Science. 264:95-98.

14. Cressmann, D.E., R.H. Diamond, and R. Taub. 1995. Rapid activation of the Stat 3 transcription complex in liver regeneration. Hepatology. 21:14431449.

15. Trautwein, C., T. Rakemann, M. Niehof, S. Rose-John, and M.P. Manns. 1996. APRF, increased binding and target gene activation during liver regeneration. Gastroenterology. 110:1854-1862.

16. Diehl, A.M., M. Yin, J. Fleckenstein, S.Q. Yang, H.Z. Lin, D.A. Brenner, J. Westwick, G. Bagby, and S. Nelson. 1994. Tumor necrosis factor- $\alpha$ induces c-jun during the regenerative reponse to liver injury. Am. J. Physiol. 267: G552-G561.

17. Diehl, A.M., S.Q. Yang, M. Yin, H.Z. Lin, S. Nelson, and G. Bagby. 1995. Tumor necrosis factor-alpha modulates CCAAT/enhancer binding proteins-DNA binding activities and promotes hepatocyte-specific gene expression during liver regeneration. Hepatology. 22:252-261.

18. Trautwein, C., T. Rakemann, A. Pietrangelo, J. Plümpe, G. Montosi, and M.P. Manns. 1996. C/EBP- $\beta /$ LAP controls downregulation of albumin gene transcription during liver regeneration. J. Biol. Chem. 271:22262-22270.

19. Trautwein, C., D. Walker, J. Plümpe, and M.P. Manns. 1995. Transactivation of LAP/NF-IL6 is mediated by an acidic domain in the N-terminal part of the protein. J. Biol. Chem. 270:15130-15136.

20. Trautwein, C., C. Caelles, P. van der Geer, T. Hunter, M. Karin, and M. Chojkier. 1993. Transactivation by LAP/NF-IL6 is enhanced by phosphorylation of its activation domain. Nature. 364:544-547.

21. Bock, C.T., H.L. Tillmann, H. Maschek, M.P. Manns, and C. Trautwein. 1997. A preS mutation isolated from a patient with chronic hepatitis B infection leads to virus retention and misassembly. Gastroenterology. 113:1976-1982.

22. Leist, M., F. Gantner, S. Jilg, and A. Wendel. 1995. Activation of the 55 $\mathrm{kDa}$ TNF receptor is necessary and sufficient for TNF-induced liver failure, hepatocyte apoptosis, and nitrite release. J. Immunol. 154:1307-1316.

23. Sherr, C.J. 1993. Mammalian G1 cyclins. Cell. 73:1059-1065.

24. Wegner, M., Z. Cao, and M.G. Rosenfeld. 1992. Calcium-regulated phosphorylation within the leucine zipper of C/EBPß. Science. 256:370-373.

25. Williams, S.C., M. Baer, A.J. Dillner, and P.F. Johnson. 1995. CRP2 $(\mathrm{C} / \mathrm{EBP} \beta)$ contains a bipartite regulatory domain that controls transcriptional activation, DNA binding and cell specificity. EMBO (Eur. Mol. Biol. Organ.) J. 14:3170-3183.

26. Horvath, C.M., Z. Wen, and J.E. Darnell. 1995. A Stat protein domain that determines DNA sequence recognition suggests a novel DNA-binding domain. Genes Dev. 9:984-994.

27. Yamada, Y., I. Kirillova, J.J. Peschon, and N. Fausto. 1997. Initiation of liver growth by tumor necrosis factor: deficient liver regeneration in mice lacking type T tumor necrosis factor receptor. Proc. Natl. Acad. Sci. USA. 94:14411446

28. Buck, M., H. Turler, and M. Chojkier. 1994. LAP (NF-IL-6), a tissuespecific transcriptional activator, is an inhibitor of hepatoma cell proliferation. EMBO (Eur. Mol. Biol. Organ.) J. 13:851-860.

29. Barone, M.V., A. Crozat, A. Tabaee, L. Philipson, and D. Ron. 1994 CHOP (GADD153) and its oncogenic variant, TLS-CHOP, have opposing effects on the induction of G1/S arrest. Genes Dev. 8:453-464.

30. Yin, M., S.Q. Yang, H.Z. Lin, M.D. Lane, S. Chatterjee, and A.M. Diehl. 1996. Tumor necrosis factor $\alpha$ promotes nuclear localization of cytokineinducible CCAAT/enhancer binding protein isoforms in hepatocytes. J. Biol. Chem. 271:17974-17978.

31. Hsu, H., H.-B. Shu, M.-G. Pan, and D.V. Goedell. 1996. TRADDTRAF2 and TRADD-FADD interactions define two distinct TNF receptor 1 signal transduction pathways. Cell. 84:299-308.

32. Liu, Z-G., H. Hsu, D.V. Goeddel, and M. Karin. 1996. Dissection of TNF receptor 1 effector functions: JNK activation is not linked to apoptosis while NF-кB activation prevents cell death. Cell. 87:565-576.

33. Leist, M., F. Gantner, I. Bohlinger, P.G. German, G. Tiegs, and A. Wendel. 1994. Murine hepatocyte apoptosis induced in vitro and in vivo by TNFalpha requires transcriptional arrest. J. Immunol. 153:1778-1787.

34. Wen, Z., Z. Zhong, and J.E. Darnell. 1995. Maximal activation of transcription by Stat 1 and Stat 3 requires both tyrosine and serine phosphorylation. Cell. 82:241-250.

35. Fukada, T., M. Hibi, Y. Yamanaka, M. Takahashi-Tezuka, Y. Fujitani, T. Yamaguchi, K. Nakajima, and T. Hirano. 1996. Two signals are necessary for cell proliferation induced by a cytokine receptor gp130: involvement of Stat 3 in anti-apoptosis. Immunity. 5:449-460.

36. Bromberg, J.F., C.M. Horvath, Z. Wen, R.D. Schreiber, and J.E. Darnell. 1996. Transcriptionally active Stat1 is required for the antiproliferative effects of both interferon $\alpha$ and interferon $\gamma$. Proc. Natl. Acad. Sci. USA. 93:76737678 .

37. Darnell, J.E., I.M. Kerr, and G.R. Stark. 1994. Jak-STAT pathways and transcriptional activation in response to IFNs and other extracellular signaling proteins. Science. 264:1415-1421. 